\title{
Mobilitat quotidiana, consum de carburants i forma urbana a la regió metropolitana de Barcelona
}

\author{
Joan López Redondo
}

Universitat Autònoma de Barcelona. Departament de Geografia

Grup d'Estudis sobre Energia, Territori i Societat

juan.lopez@uab.cat

Recepció: octubre de 2015

Acceptació: maig de 2016

\section{Resum}

El consum de carburants produït per la mobilitat laboral a la regió metropolitana de Barcelona està estretament relacionat amb la morfologia dels teixits urbans. Per demostrar-ho, el present treball desenvolupa una metodologia destinada a 1) superar les mancances de dades de mobilitat actuals amb un elevat nivell de desagregació territorial; 2) assignar un consum de carburant a cada flux de mobilitat en funció del seu volum, de la distància recorreguda i dels mitjans de transport utilitzats, i 3) creuar els resultats de cada municipi amb una classificació del seu sòl residencial. Els resultats permeten constatar l'existència de diferències notables en el consum de carburants dels municipis que poden explicar-se, en bona part, per les característiques del sòl residencial.

Paraules clau: mobilitat; consum d'energia; carburants; tipologia residencial; forma urbana

Resumen. Movilidad cotidiana, consumo de carburantes y forma urbana en la región metropolitana de Barcelona

El consumo de carburantes producido por la movilidad laboral en la región metropolitana de Barcelona está estrechamente relacionado con la morfología de los tejidos urbanos. Para demostrarlo, el presente trabajo desarrolla una metodología destinada a 1) superar las carencias de datos de movilidad actuales con un elevado nivel de desagregación territorial; 2) asignar un consumo de carburante a cada flujo de movilidad en función de su volumen, de la distancia recorrida y de los medios de transporte utilizados, y 3) cruzar los resultados de cada municipio con una clasificación de su suelo residencial. Los resultados permiten constatar la existencia de notables diferencias en el consumo de carburantes de los municipios que pueden ser explicadas, en buena medida, por las características de su suelo residencial.

Palabras clave: movilidad; consumo de energía; carburantes; tipología residencial; forma urbana 
Résumé. Mobilité quotidienne, consommation de carburant et forme urbaine dans la région métropolitaine de Barcelone

La consommation de carburant produite par la mobilité professionnelle dans la région métropolitaine de Barcelone est étroitement liée à la morphologie du tissu urbain. Pour le démontrer, l'article développe une méthodologie dans l'objectif de 1) combler les lacunes des données actuelles de mobilité avec un niveau de découpage territorial élevé; 2) attribuer la consommation de carburant à chaque flux de mobilité en fonction de son volume, de la distance parcourue et des moyens de transport utilisés, et 3) recouper les résultats obtenus dans les municipalités avec une classification de leur terrain résidentiel. Les résultats permettent de déterminer l'existence de différences significatives dans la consommation de carburant des municipalités qui peuvent être expliquées en grande partie par les caractéristiques de leur terrain résidentiel.

Mots-clés: mobilité; consommation d'énergie; carburant; typologie résidentielle; forme urbaine

Abstract. Daily mobility, fuel consumption and urban form in the metropolitan region of Barcelona

Fuel consumption produced by travel to work in the metropolitan region of Barcelona is closely linked to the morphology of the urban fabric. In order to demonstrate this affirmation, this paper develops a methodology to 1) overcome the lack of mobility data at the local scale; 2) assign fuel consumption to each mobility flow depending on its size, the distance travelled and the transport mode used, and 3) cross results by municipalities with a classification of their residential land. The results confirm that municipalities show significant differences in fuel consumption, which can be explained to a large extent by the characteristics of the residential land.

Keywords: mobility; energy consumption; fuel; residential typology; urban form

\section{Sumari}

1. Introducció 4. Resultats: la relació entre consum

2. L'estudi de la relació entre mobilitat quotidiana, consum de carburant i forma urbana

3. Metodologia: estimació del consum de carburants de la mobilitat laboral en relació amb la tipologia residencial de carburants i forma urbana

5. Conclusions

Referències bibliogràfiques

Annex. Exemple d'estimació del consum de carburant per a un flux de mobilitat laboral 


\section{Introducció}

El present treball té per objectiu identificar la relació entre el consum de carburants atribuïble a la mobilitat laboral i les característiques dels teixits residencials de la regió metropolitana de Barcelona. En aquest sentit, l'article parteix de la hipòtesi que els municipis amb teixits residencials predominantment dispersos i/o de baixa densitat mostren una proporció més elevada de desplaçaments laborals efectuats en vehicles privats, i que aquests desplaçaments cobreixen distàncies més llargues que les recorregudes pels residents en municipis densos i compactes. Consegüentment, el consum de carburant per treballador ocupat serà molt superior en el primer tipus, és a dir, la mobilitat generada en municipis de baixa densitat implica, de mitjana, consums de carburant per desplaçament laboral força superiors als de la resta de poblacions. L'article s'estructura en tres parts més un darrer apartat de conclusions.

La primera part fa una revisió de les fonts estadístiques i dels estudis sobre mobilitat disponibles a Catalunya. L'empobriment de la quantitat i de la qualitat de dades en comparació amb les disponibles anys enrere explica no únicament la disminució d'anàlisis territorials basades en la mobilitat, sinó també la necessitat de recórrer a metodologies complexes per estudiar la dimensió territorial de la mobilitat.

Constatada aquesta necessitat, la segona part descriu la metodologia desenvolupada per conèixer tant les relacions actuals de mobilitat dels municipis de la regió metropolitana de Barcelona (orígens i destinacions, distàncies recorregudes i mitjà de transport utilitzat) a partir de les dades existents, com els consums de carburants atribuïbles a aquesta mobilitat. Aquest consum, un cop dividit pel nombre d'ocupats residents a cada municipi, ha pogut ser creuat amb informació sobre les característiques del seu teixit residencial.

La tercera part mostra els resultats del creuament de les observacions obtingudes, tant pel que fa a la mobilitat com a les característiques dels teixits residencials. D'aquesta manera, s'ha pogut constatar la relació existent entre consum de carburants i forma urbana. Val a dir que el valor principal dels resultats assolits no resideix tant en la quantificació exacta del consum de carburants de cada municipi com en la comparació d'aquests resultats entre municipis amb tipologies residencials distintes. En efecte, tot i que la utilització de dades molt diverses i la successió de tractaments estadístics a què han estat sotmeses comporta una inevitable acumulació d'errors, la utilització de les mateixes fonts i l'aplicació de la mateixa metodologia per a tots els municipis permet valorar de manera prou consistent les diferències relatives de consum de carburant en funció del teixit residencial.

\section{L'estudi de la relació entre mobilitat quotidiana, consum de carburant i forma urbana}

La relació entre forma urbana i mobilitat quotidiana i consum de carburants ha estat àmpliament analitzada des del punt de vista internacional. Val a dir, però, 
que bona part d'aquestes anàlisis es basen en la comparació de ciutats o d'àrees metropolitanes a escala continental o fins i tot planetària, i no en les eventuals diferències existents a l'interior de cadascuna d'aquestes àrees (Karathodorou et al., 2010, Van de Coevering i Schwanen, 2006). En molts casos, a més, es tracta d'anàlisis multivariables, on la disparitat de criteris sobre el nombre i el tipus de variable que es consideri proporcionen resultats clarament divergents $i$, de vegades, contradictoris. De fet, el debat sorgit arran d'aquestes divergències en els resultats ha estat recollit per diversos autors (Hickman i Banister, 2007; Shim et al., 2006; Banister, 2012) i dóna mostra no únicament de la dificultat d'establir una metodologia d'anàlisi àmpliament consensuada, sinó també de la complexitat de comparar les pautes de mobilitat i consum de carburant corresponents a realitats urbanes diverses.

A Catalunya, les anàlisis de la relació entre mobilitat i forma urbana han estat molt menys abundants, fins i tot en el període 1981-2001, en què la disponibilitat d'informació estadística consistent, detallada i exhaustiva territorialment, va permetre que sorgissin nombroses anàlisis sobre mobilitat quotidiana. La inclusió en els qüestionaris d'estadística associada als padrons municipals i als censos de població de preguntes relatives a la ubicació del lloc de treball de la població ocupada, el mitjà de transport utilitzat per anar a treballar $\mathrm{i}$, posteriorment, altres preguntes més detallades, va permetre conèixer de manera força fiable quines eren les relacions diàries de mobilitat obligada (laboral i d'estudi) a Catalunya: quin volum de persones treballava en el seu propi municipi o fora, com hi arribaven $i$, sobretot, cap a on es desplaçaven.

Aquesta informació de base sobre la mobilitat quotidiana va permetre realitzar nombrosos treballs i estudis amb enfocaments i objectius diferents. Així, es troben des d'anàlisis adreçades a explicar l'estructura territorial (Nel.lo [dir.], 1999; Nel.lo et al., 2002; López, 1998) fins a aquelles que utilitzaven les dades de mobilitat com a informació de base per delimitar unitats territorials cohesionades (Lluch et al., 1968; Clusa, 1995; Roca, 1997, 1998a, 1998b; Castañer, 1994a, 1994b; Palacio, 1995; AADD, 1998; Grup d'Anàlisi i Planificació Territorial i Ambiental, 2005). Al costat seu, hi trobem també treballs que tenien com a objectiu principal alertar sobre les conseqüències, principalment negatives, d'un manteniment de les taxes d'increment de la mobilitat observades (Nel.lo, 1995; Miralles, 1997; López, 2003).

Totes aquestes anàlisis varen gaudir d'un nivell creixent de reconeixement, tant en els entorns acadèmics com de l'Administració responsable de l'ordenació del territori, i fins i tot esdevingueren una de les bases sobre la qual es van formular propostes de planejament territorial (Generalitat de Catalunya. Departament de Política Territorial i Obres Públiques, 1995, 2010; Carrera i López, 2006; Carrera [dir.], 2012).

Després d'aquell període, però, la mobilitat ha deixat de ser un element bàsic d'anàlisi territorial. La raó principal d'aquesta pèrdua de protagonisme cal buscar-la no ja en la idoneïtat de les dades per als objectius de l'anàlisi, sinó, simplement, en la seva inexistència, com a mínim amb el nivell de desagregació territorial que hi havia. En efecte, a partir de 2001, les dades disponibles pro- 
cedents de fonts registrals han deixat de proporcionar la informació necessària per realitzar l'anàlisi territorial de la mobilitat ${ }^{1}$. Per aquest motiu, a la regió metropolitana de Barcelona, les úniques dades disponibles van passar a ser les provinents de les enquestes, ja fossin de caràcter general o específiques sobre mobilitat (Autoritat del Transport Metropolità, 2014; Institut d'Estudis Regionals i Metropolitans de Barcelona, 2002, 2004). Com és sabut, però, la pròpia metodologia de les enquestes obliga a limitar l'amplitud de la mostra, que, en el cas de les fonts padronals i censals, corresponia a pràcticament el $100 \%$ de la població. Aquesta reducció de la mostra esdevé fatal per a l'anàlisi territorial, que requereix el nivell màxim de desagregació (i, per tant, representativitat en totes les unitats territorials, per petites que siguin), per tal de proporcionar resultats significatius. D'aquesta manera, els estudis basats en enquestes, de gran valor per al coneixement de determinats aspectes de la mobilitat, són insuficients per identificar el sistema de relacions territorials per sota d'una escala comarcal $^{2}$. Únicament els treballs realitzats per a àmbits territorials específics permeten ampliar aquesta fiabilitat estadística ${ }^{3}$.

1. La introducció del padró continu l'any 1998, en substitució dels tradicionals padrons d'habitants que es realitzaven cada cinc anys, va representar una millora en referència a la fiabilitat $i$, sobretot, a l’actualització de la informació sobre la població resident a cada municipi, però, en limitar la informació recollida a cinc variables bàsiques (sexe, edat, lloc de naixement, nacionalitat $\mathrm{i}$, lògicament, municipi de residència), no permet fer l'estudi de la mobilitat. D'altra banda, el Cens de població $i$ habitatge, que es du a terme cada deu anys, en realitzar-se a través d'una enquesta per mostreig a partir de 2011, impedeix obtenir dades representatives per a determinats creuaments de variables (entre les quals trobem les relacions de mobilitat) en la gran majoria de municipis. L'altra font important de dades registrals sobre mobilitat, les provinents dels comptatges, ja sigui de bitllets de transport públic o d'aforaments en la xarxa viària, no permeten analitzar el conjunt de desplaçaments, en limitar-se a uns mitjans de transport específics; a més, en el segon cas, la precisió de la localització territorial fa referència a punts dels recorreguts, i no a inicis o finals, per la qual cosa esdevé impossible establir-hi relacions territorials d'origen i destinació.

2. En aquest sentit, han estat tres les grans fonts de referència a la regió metropolitana de Barcelona. En primer lloc, l'Enquesta de mobilitat en dia feiner (EMEF), hereva de les enquestes de mobilitat de l'Ajuntament de Barcelona i l'Entitat Metropolitana del Transport iniciades a la dècada de 1980 i realitzada per l'Autoritat del Transport Metropolità amb periodicitat anual des de 2003. En segon lloc, l'Enquesta de mobilitat quotidiana (EMQ), realitzada també per l'ATM, amb una metodologia i una mostra més complexes que l'EMEF, la qual cosa va obligar a restringir-ne les edicions (1996 i 2001 per a la regió metropolitana i 2006 ampliada al conjunt de Catalunya) i, finalment, a interrompre-la l'any 2011. Al seu costat, l'Enquesta de condicions de vida $i$ hàbits de la població, realitzada quinquennalment per l'Institut d'Estudis Regionals i Metropolitans de Barcelona des de 1986, tot i ser de caire general, conté preguntes referents a l'ús del territori que han constituït una font d'informació de gran valor per a l'estudi de la mobilitat.

3. Als treballs específics de molts municipis elaborats per als seus plans de mobilitat o per als seus plans d'acció en referència a l'energia sostenible, cal afegir-hi anàlisis per a àrees específiques d'activitat. N'és un exemple el que l'Enquesta d'hàbits de la mobilitat que la Universitat Autònoma de Barcelona, a través de la Unitat de Planificació i Gestió de la Mobilitat de la UAB i el Grup d'Estudis de Mobilitat, Transport i Territori (GEMOTT), del Departament de Geografia, realitza des de fa més de deu anys (vegeu <http://www.uab. cat/web/la-mobilitat-a-la-uab/enquesta-de-mobilitat-1255501888126.html>). 
Tan sols darrerament, el creuament de dades provinents de diverses fonts ha permès disposar un altre cop d'informació sobre l'estructura territorial de la mobilitat. En el cas de la mobilitat per motius laborals, ens referim a les Afiliacions a la Seguretat Social segons residència padronal de l'afiliat, obtingudes, com el seu nom indica, a partir del creuament de les dades relatives a la població ocupada provinents de la Tresoreria General de la Seguretat Social, amb informació relativa al municipi de residència provinent del Registre de població de Catalunya.

Al llarg dels propers anys, probablement tindrem accés a dades noves de mobilitat recollides a partir de metodologies dissenyades per aprofitar les gairebé infinites possibilitats que ens ofereixen les tecnologies de la informació, com ara les aplicacions instal.lades als telèfons mòbils de la població, que, acompanyades pels sistemes de geolocalització, oferiran un ampli i detallat ventall d'informació sobre els orígens, les destinacions, els recorreguts, la durada, els mitjans o moltes variables més relacionades amb la mobilitat de la població ${ }^{4}$. De moment, però, la disponibilitat d'aquestes dades en referència a un àmbit territorial com la regió metropolitana de Barcelona està subjecta a la realització d'una complexa tasca d'estandardització de la metodologia i l'extensió de la seva aplicació. Per tant, els estudis i les anàlisis que se'n deriven encara són incipients.

Com a conseqüència d'aquesta situació, a Catalunya, les dades sobre mobilitat amb un nivell elevat de desagregació territorial són, en l'actualitat, pràcticament inexistents. Aquest dèficit d'informació ha estat en gran part responsable del reduït nombre d'anàlisis que permetin establir la relació de la mobilitat amb unes altres variables territorials, com ara la tipologia urbana. Així, els nombrosos treballs que alertaven sobre els costos de la baixa densitat i la dispersió a la regió metropolitana de Barcelona (Rueda, 2002; Indovina, 2007; Nel.lo, 2011a; Muñoz, 2011) han servit perquè la importància de la forma urbana com a condicionant de la mobilitat hagi estat reconeguda per part de les administracions responsables a partir de plans i d'estratègies (Autoritat del Transport Metropolità, 2015; Ministerio de Medio Ambiente, 2011), si bé la seva evidència empírica ha estat poc contrastada. Tan sols alguns autors (De la Fuente, 2007, 2012) han utilitzat les dades censals de 2001 per analitzar la influència de la forma urbana (entesa aquí d'acord amb un concepte que va més enllà de la densitat i de la dispersió dels teixits residencials) en dos components específics de la mobilitat, com ara la tinença de vehicle privat $\mathrm{i}$ l'elecció del mode de transport utilitzat en els desplaçaments. Les mateixes dades censals han estat utilitzades per observar la incidència del policentrisme sobre la mobilitat laboral a diverses àrees metropolitanes espanyoles (Marmolejo i Tornés, 2015).

4. Val a dir que ja són múltiples les iniciatives que han sorgit en aquest sentit. Entre altres, la mateixa Universitat Autònoma de Barcelona ha desenvolupat el projecte Campus Mobility a partir d'una aplicació per a Android que permet monitoritzar els desplaçaments dels voluntaris inscrits en el projecte. L'aplicació es pot descarregar a: <https://play.google.com/ store/apps/details?id=net.movelab.mobility\&hl=ca>. 
Quan es tracta, a més, d'estimar el consum de carburants associat a aquesta mobilitat, els àmbits territorials considerats difícilment baixen a l'escala municipal. En la majoria de casos, són quantificacions relatives al conjunt de la regió metropolitana que, malgrat que hagin estat realitzades amb un nivell elevat de detall, parteixen de registres no territorialitzables en origen, com poden ser les intensitats mitjanes diàries dels aforaments assignades al graf viari (Institut Cerdà, 2012; Sener, 2012). Aquesta limitació és deguda a la dificultat d'assignar el consum a escala local que, a diferència d'altres fonts d'energia, presenten els hidrocarburs per a automoció. De fet, els pocs treballs que territorialitzen informació sobre consum energètic a nivell municipal alerten sovint de les limitacions dels resultats oferts en el cas específic dels hidrocarburs (Direcció de Serveis Ambientals de l'AMB. Barcelona Regional, 2014) $)^{5}$. Per aquest motiu, les estimacions de consum de carburants associat a la mobilitat que busquen un detall territorial elevat no es basen en registres directes d'adquisició de carburants, sinó en estimacions a partir del nombre i de les característiques dels desplaçaments. La necessitat de recórrer a dades de mobilitat desagregades territorialment per tal d'estimar el consum de carburants a escala local, juntament amb la manca d'aquestes dades en l'actualitat, ha provocat que les poques anàlisis o aproximacions existents a Catalunya facin referència a l'any 2001 o fins i tot a períodes anteriors (Muñiz i Galindo, 2005).

En aquest context, esdevé fonamental desenvolupar una metodologia que actualitzi els fluxos de mobilitat laboral de la matriu de 2001 i que calculi el consum de carburants a partir de les distàncies i el mitjà de transport dels desplaçaments. Només així és possible posar en relació els consums de carburants amb les característiques de la morfologia urbana de cada municipi.

\section{Metodologia: estimació del consum de carburants de la mobilitat laboral en relació amb la tipologia residencial}

En el present treball, l'anàlisi de la relació entre tipologia residencial i consum de carburants per mobilitat laboral s'ha realitzat en dues fases metodològiques. En primer lloc, s'ha efectuat l'estimació del consum a partir de les dades obtingudes sobre mobilitat laboral i, a continuació, s'han creuat aquests resultats amb les característiques del sòl residencial de cada municipi. Vegem, a continuació, com s'ha dut a terme el desenvolupament d'aquestes fases.

5. El treball realitzat per l'Àrea Metropolitana de Barcelona i Barcelona Regional per als 36 municipis de l'AMB, no únicament destaca la dificultat de disposar de dades de consum energètic a nivell municipal, sinó que, en el cas específic dels hidrocarburs, adverteix a cada fitxa municipal que «l'obtenció de dades de consum energètic d'hidrocarburs no és senzilla, ja que no es poden obtenir de manera directa, en no haver-hi una escomesa ni un comptador al punt de consum de l'usuari, com passa amb el consum elèctric i de gas natural. Per tant, sempre trobarem que aquestes dades són estimades mitjançant càlculs indirectes on poden intervenir la població, la circulació de vehicles o d'altres variables». 


\subsection{Estimació del consum de carburants per municipi}

L'estimació del consum de carburants per municipi ha constat de sis passos successius: actualització de la matriu de mobilitat, assignació de les distàncies, assignació del mitjà de transport, assignació dels consums per mitjà de transport, assignació de places per vehicle i conversió dels consums de carburants a unitats d'energia.

\subsubsection{Actualització de la matriu de mobilitat}

El dinamisme econòmic, social i territorial de la regió metropolitana ha comportat una transformació notable de la seva base productiva i de la seva estructura social, la qual cosa inclou, lògicament, una relocalització tant de les activitats econòmiques com de la residència de la seva població (Carrera [dir.], 2012; Trullén [dir.], 2015; Villalante et al., 2014). Aquest doble moviment ha alterat, com no podia ser de cap més manera, les relacions de mobilitat laboral entre els municipis. Si bé, com ja ha estat apuntat, la localització exacta dels llocs de treball (les destinacions) és una tasca especialment difícil, l'actualització de localització de la residència (els orígens) és possible avui gràcies a les noves explotacions estadístiques de la dades de la Seguretat Social que elabora l'Institut d'Estadística de Catalunya. Així, les dades sobre Afiliats $i$ afiliacions a la Seguretat Social segons residència padronal de l'afiliat (tant del Règim General com d'Autònoms) s'obtenen a partir de la comparació entre el municipi de residència i el municipi del centre de cotització en què es troba inscrit el treballador. Del creuament d'aquests dos punts, se n'extreu un flux hipotètic d'origen-destinació ${ }^{6}$. Aquest creuament, però, presenta una doble limitació. La primera deriva d'haver d'emprar com a destinació el centre de cotització del treballador, ja que, com és sabut, una empresa el pot tenir situat en un municipi diferent del lloc o dels llocs on realitza l'activitat. L'àmbit territorial màxim per a un centre de cotització és la província, això vol dir que, en principi, tots els treballadors, es trobin on es trobin d'aquella província, podrien arribar a constar en un únic municipi. D'altra banda, el creuament entre les dues fonts citades permet fer una interpretació d'un hipotètic desplaçament, però no descriu aquest desplaçament $\mathrm{i}$, menys encara, permet associar-hi cap més característica, com ara el temps emprat, les distàncies recorregudes o el mitjà de transport utilitzat. Tenint en compte aquestes limitacions, el procediment seguit ha consistit a distribuir el nombre total d'ocupats de cada municipi que ofereixen les dades d'afiliació corresponents al primer trimestre de 2015 en fluxos de mobilitat laboral, segons la darrera matriu origen-destinació disponible per a tots els municipis metropolitans, la corresponent al cens de població

6. Els creuaments han estat realitzats per l'Institut d'Estadística de Catalunya. El mateix Idescat realitza de manera similar l'Estadística de la mobilitat obligada per raó d'estudi (tant escolar com universitari) a partir del creuament entre el lloc de residència dels alumnes i la localització del centre d'ensenyament on estan matriculats. 
de $2001^{7}$. D'aquesta manera s'ha obtingut una actualització de la matriu de mobilitat $^{8}$.

\subsubsection{Assignació de les distàncies}

A aquesta matriu origen-destinació per municipis, s'hi han afegit les distàncies entre cada parell de punts. Aquestes distàncies han estat calculades a partir d'un únic node per a cada municipi, corresponent al centroide determinat a la Base municipal 1:50.000 de l'Institut Cartogràfic i Geològic de Catalunya?. Respecte als desplaçaments intramunicipals, en tots els casos, s'hi ha aplicat una distància mitjana de 1.000 metres ${ }^{10}$. Respecte als desplaçaments «A la resta de l'Estat» $\mathrm{i}$ "A l'estranger», s'hi ha aplicat en tots els casos una distància mitjana de 150 quilòmetres. S'ha obviat la categoria "Ocupats en un lloc de treball que està ubicat a diversos municipis», ja que la matriu no en distingeix el mode de transport i hi assigna l'epígraf genèric de «No aplicable».

\subsubsection{Assignació del mitjà de transport}

Per tal d'assignar els consums a cada mitjà de transport, s'ha considerat el desglossament per modes de la mateixa matriu del cens de 2001. Aquest desglossament constava de 50 categories. En les categories compostes («Cotxe com a

7. La matriu de mobilitat laboral per als desplaçaments originats en els 164 municipis de la regió metropolitana de Barcelona i amb destinació als 946 municipis de Catalunya existents l'any 2001, més la resta de l'Estat, l'estranger i els fluxos no aplicables (per destinació a més d'un municipi), donà 15.867 relacions origen-destinació amb un desplaçament o més per flux.

8. Una aproximació més ajustada hauria de considerar la relació entre l'afiliació i l'ocupació declarada censalment, per tal d'evitar comptatges dobles corresponents a afiliacions dobles. La comparació entre el total de població ocupada resident a Catalunya l'any 2001 - 2.815.126 ocupats — i el d'afiliats el segon semestre del mateix any - 2.822.166 — són pràcticament coincidents, per la qual cosa no s'ha considerat necessari minorar el nombre d'afiliats aplicant-los un pràcticament inapreciable coeficient de 0,9975 .

9. La base de centroides ha estat tractada amb GIS per tal d'obtenir les distàncies euclidianes entre cada parell de punts. El fet de considerar les distàncies euclidianes i no les existents segons la xarxa viària respon a la dificultat d'assignar els desplaçaments a un únic recorregut, a causa de la duplicitat de vies possibles en la major part dels fluxos. En qualsevol cas, les diferències entre els recorreguts segons el viari i les distàncies euclidianes obtingudes, a més de ser poc significatives en la majoria de casos, tendeixen a compensar-se en considerar dades agregades per a tota la matriu.

10. Marmolejo i Tornés (2015), per exemple, estableixen una distància variable per a cada municipi a partir de la superfície de sòl urbà. Aquest criteri és especialment indicat per a aproximacions en què el sòl urbà és considerat a partir de grans àrees ciutadanes prèviament delimitades com a tals. En el present treball, en què es considera únicament el sòl residencial net, és a dir, el que equivaldria urbanísticament a les zones privades de sòl residencial, l'aplicació d'aquest criteri quedaria distorsionada per la gran dispersió de molts municipis, ja que l'agregació de moltes superfícies petites però molt distants entre si donaria com a resultat una distància molt inferior a la que es produeix realment entre aquestes àrees urbanes. Per aquest motiu, davant la impossibilitat de trobar un valor per a cadascun dels 164 municipis metropolitans i, dintre d'aquests, per a cadascun dels mitjans de transport analitzats, s'ha optat per aquest valor mitjà, sent conscients que la seva aplicació pot presentar en alguns casos un clar biaix respecte a la distància real. 
conductor + autobús», "Autobús + metro», etc.), majoritàries en nombre, si bé menys importants pel que fa al volum de desplaçaments aplegats, les distàncies dels desplaçaments s'han dividit a parts iguals entre un mode i l'altre. És a dir, en el cas d'un recorregut de, per exemple, 20 quilòmetres realitzat amb cotxe + autobús, s'hi han assignat els 10 primers quilòmetres de distància al primer mitjà i els altres $10 \mathrm{al} \mathrm{segon.} \mathrm{Finalment,} \mathrm{en} \mathrm{referència} \mathrm{al} \mathrm{càlcul,} \mathrm{s'han} \mathrm{obviat}$ totes aquelles categories que no consumeixen hidrocarburs líquids directament ${ }^{11}$. En les categories compostes entre el primer tipus de mitjans i el segon, s'ha considerat únicament la part corresponent al consumidor d'hidrocarburs.

\subsubsection{Assignació dels consums per mitjà de transport}

En primer lloc, a la categoria "Cotxe com a conductor» (la categoria "Cotxe com a passatger» ha estat igualment obviada, per evitar comptabilitats dobles), s'ha distingit entre vehicles de gasolina i vehicles de gasoil, aplicant-hi un $49,77 \%$ i un $50,23 \%$ del total, respectivament ${ }^{12}$. A partir d'aquí, s'han assignat els consums mitjans de carburant per cada mitjà de transport, tot distingint entre cotxe de gasolina $(7,975 \mathrm{l} / 100 \mathrm{~km})$, cotxe de gasoil $(5,784 \mathrm{l} / 100 \mathrm{~km})^{13}$, moto $(3 \mathrm{l} / 100 \mathrm{~km})^{14}$ i autobús $(32,71 \mathrm{l} / 100 \mathrm{~km})^{15}$.

11. Concretament, les categories «Metro», «Renfe», «Altres trens», «Bicicleta», «Caminant», "Altres mitjans» $\mathrm{i}$ totes les compostes exclusives derivades d'aquestes, així com l'esmentada categoria «No aplicable». Es considera que aquestes categories fan referència a opcions de desplaçament no consumidores directes d'hidrocarburs, malgrat que n'hi ha algunes, d'alimentades per energia elèctrica, que ho poden ser de manera indirecta, per la utilització de gasoil, fuel o, també, gas natural en les centrals de generació.

12. Es tracta del repartiment entre aquestes categories del parc de turismes existent a la província de Barcelona l’any 2014, segons les dades del Parque de vehículos - Anuario - 2014, de la Direcció General de Trànsit: <http:/www.dgt.es/es/seguridad-vial/estadisticas-e-indicadores/parque-vehiculos/tablas-estadisticas/2014/>.

13. Els consums mitjans, tant si fan referència al cotxe de gasolina com al de gasoil, han estat calculats a partir de la fórmula i dels paràmetres continguts a l'annex 1.2 final del «Real Decreto 837/2002, de 2 de agosto, por el que se regula la información relativa al consumo de combustible y a las emisiones de $\mathrm{CO}_{2}$ de los turismos nuevos que se pongan a la venta o se ofrezcan en arrendamiento financiero en territorio español i la posterior Resolución de 24 de septiembre de 2012, de la Secretaría General de Industria y de la Pequeña y Mediana Empresa, por la que se actualiza el anexo I.2 del Real Decreto 837/2002, de 2 de agosto, en lo relativo a los parámetros que determinan la media del consumo de los vehículos de turismo nuevos que se pongan a la venta o se ofrezcan en arrendamiento financiero en territorio español», calculats, en tots dos casos, per a un vehicle mitjà de 4,4 metres de llarg i 1,75 metres d'ample.

14. Per a les motos, s'ha estimat un consum mitjà a partir de les dades sobre els deu models més venuts de gener a juliol de 2015 segons el portal masmoto.net. El mateix portal ofereix fitxes tècniques per a cada model, si bé són molt poques les que mostren informació sobre consum.

15. A causa de les dificultats per aplicar un únic coeficient de consum per a la gran diversitat d'autobusos i rutes existents, se n'ha aplicat un de mitjà de $32,71 \mathrm{l} / 100 \mathrm{~km}$, ofert com a mitjana per a l'any de la matriu origen-destinació de referència, el 2001, segons recull el Butlletí de transports, núm. 26, desembre de 2003, de l'Observatori de Catalunya Transport Regular de Viatgers per Carretera de la Generalitat de Catalunya. 


\subsubsection{Assignació de places per vehicle}

Finalment, en fer referència a les dades de mobilitat a persones però també a les de consum a vehicles, ha calgut estimar una relació entre totes dues variables per tal d'assignar el consum a cada persona. En el cas del cotxe i la moto, en obviar la categoria "Cotxe com a passatger», cada unitat de persones és equivalent a una unitat de vehicles. En el cas de l'autobús, però, com que hi ha diversos usuaris que comparteixen un mateix vehicle, només es pot atribuir una part del seu consum a cada usuari. El coeficient que assigna aquesta part s'ha establert en 0,055, resultat de dividir 1 entre 18,29, que ha estat considerada l'ocupació mitjana per autobús ${ }^{16}$.

\subsubsection{Conversió dels consums de carburants a unitats d'energia}

L'aplicació d'aquests coeficients diversos al valor de cada cel.la de la matriu origen-destinació de mobilitat laboral dels municipis metropolitans desglossada per modes de transport ha permès estimar-ne el consum en litres, tant de gasoil com de gasolina. Per tal d'oferir una única quantitat en termes d'energia, aquestes magnituds en litres han esta convertides a quilograms equivalents de petroli (kep) ${ }^{17}$.

La taula de l'annex mostra com a exemple el tractament realitzat a un flux de mobilitat dels 15.867 exemples tractats al conjunt de la matriu. Es tracta del flux Sabadell-Cerdanyola del Vallès, on es mostren, pas per pas, tant els paràmetres considerats com la seva aplicació a aquest flux concret. El resultat final expressa els quilograms equivalents de petroli consumits de manera directa per tots els mitjans de transport motoritzats. El sumatori d'aquest resultat amb la resta de fluxos originats a Sabadell i amb destinació a la resta de municipis és el consum total d'energia atribuïble a aquella població ${ }^{18}$.

16. El nombre mitjà d'usuaris per autobús és igualment difícil de sintetitzar, en existir una gran diversitat de vehicles i de tipus de rutes. En aquesta estimació, s'ha considerat la xifra de 18,29 , perquè és el valor mitjà dels cinc tipus de línies considerades $(\mathrm{A}, \mathrm{B}, \mathrm{C}, \mathrm{D}$ i E, on els dos primers corresponien a línies que no passaven ni paraven dins del terme municipal de Barcelona, mentre que els tres darrers corresponien a línies que hi tenien parada, inici o final de trajecte) que oferia l'esmentat Butlleti de transports per a l'any de la matriu origendestinació utilitzada.

17. La conversió ha estat realitzada a raó de 0,7752 kep per litre de gasolina i 0,84674 kep per litre de gasoil, segons els factors oferts per l'Instituto para la Diversificación y Ahorro de la Energía: Factores de conversión energía final-energía primaria y factores de emisión de co2-2011 (<http://www.idae.es/uploads/documentos/documentos_Factores_Conversion_Energia_y_ CO2_2011_0a9cb734.pdf >).

18. Val a dir que, tot i que, a partir del sumatori dels resultats obtinguts per a tots els municipis, es pot obtenir una estimació total del consum de carburants, el treball no persegueix aquest objectiu ni el considera apropiat. Així, cal tenir en compte que es tracta d'una estimació realitzada amb objectius de comparació, no de quantificació en termes absoluts. La magnitud total obtinguda no fa referència al consum anual, sinó a un hipotètic consum diari (tampoc es pot especificar si es tracta de dies laborables, ja que el conjunt d'ocupats residents a la regió metropolitana treballen de manera no homogènia al llarg de tota la setmana). A més, es basa en els desplaçaments realitzats per un motiu específic, el laboral, que, en molts casos, és possible que s'entrelligui amb altres motivacions de desplaçament no contemplades 
L'estimació del consum de carburants esdevé, d'aquesta manera, un indicador que permet aglutinar tres de les característiques bàsiques derivades de la mobilitat laboral municipal: volum, distàncies recorregudes i mitjà de transport utilitzat.

\subsection{Identificació de la tipologia residencial dels municipis}

La base per identificar les tipologies urbanes ha estat la quarta edició del Mapa de cobertes del sòl de Catalunya, del Centre de Recerca Ecològica i Aplicacions Forestals (CREAF), corresponent a l'any 2009.

Aquesta base divideix i classifica la superfície de la regió metropolitana de Barcelona en 279.448 polígons en funció del tipus de coberta del sòl. Aquests polígons són classificats a partir de quatre camps («Tipus de cobertes compostes», «Tipus d'edificació», «Tipus de cobertes simples» $\mathrm{i}$ «Coberta en construcció»), que donen com a resultat 411 categories $^{19}$. D'aquestes categories, se n'han seleccionat únicament sis, aquelles que corresponen a teixits residencials de manera plena i inequívoca: "Centre urbà», «Eixample», "Colònies i nuclis aillats», «Habitatges unifamiliars», "Cases ailllades» $\mathrm{i}$ «Urbanitzacions». La resta de cobertes n'han estat descartades, incloses aquelles que puguin ser considerades pròpies de teixits urbans (i que, fins i tot, tinguin règim d'urbà en les classificacions municipals). Es tracta de categories com ara "Els parcs urbans», «Els equipaments educatius», «Els equipaments sanitaris» o «Les activitats industrials i terciàries». Les categories seleccionades són, per tant, superfícies residencials depurades (o pràcticament netes, tot i que s'hi incorporen uns altres tipus de superfícies, com ara, per exemple, l'eix viari local) que ocupen en total les esmentades 39.549 hectàrees, és a dir, un $12,2 \%$ de les 323.600 hectàrees de la regió metropolitana de Barcelona.

En aquest treball, s'ha distingit entre les tres primeres categories esmentades $\mathrm{i}$ les tres darreres, de manera que les cobertes «Habitatges unifamiliars», "Cases aïllades» $\mathrm{i}$ «Urbanitzacions» es consideren com a sòl residencial dispers i de baixa densitat, i la resta, com a sòl dens i compacte. Aquesta classificació en dues úniques categories obvia característiques del teixit urbà com ara la mixtura d'usos, àmpliament estudiades per alguns autors (Cervero i Duncan, 2006), o variables relacionades amb la població, l'activitat econòmica o les infraestructures (De la Fuente, 2007), perquè s'ajusten millor a l'objectiu de simplificació dels resultats de la present anàlisi, com és la diferenciació del sòl residencial en funció de les característiques morfològiques bàsiques que presenta.

La caracterització dels municipis metropolitans en funció de la seva proporció de sòl residencial dispers i de baixa densitat serà precisament la que servirà per creuar els resultats de consum de carburants a la darrera part de l'anàlisi.

en aquesta anàlisi. El valor principal d'aquest càlcul de carburants és, com s'ha dit, la possibilitat de comparar entre els diversos municipis metropolitans i la relació que s'estableix amb les seves característiques urbanes.

19. Les bases cartogràfiques del Mapa de cobertes del sòl de Catalunya es poden descarregar en format vectorial al portal web del CREAF: <http://www.creaf.uab.es/mcsc/descriptiu.htm>. 


\section{Resultats: la relació entre consum de carburants i forma urbana}

L'estimació del consum de carburants per ocupat dóna resultats sensiblement diferents en els diversos municipis metropolitans. Així, si bé la mitjana és de 0,208 quilos equivalents de petroli (kep) per ocupat, alguns municipis mostren valors inferiors, mentre que molts d'altres, la majoria, es troben clarament per sobre d'aquesta xifra. Entre els primers, destaca el municipi de Barcelona, amb 0,109 kep/ocupat, molt per sota de qualsevol altre, a causa molt probablement de la combinació de dos factors: l'elevada autocontenció laboral que presenta i l'oferta de transport col-lectiu que hi ha, a banda, logicament, de l'elevat percentatge de desplaçaments a peu.

El mapa 1 permet observar que la resta de municipis de l'entorn més proper a Barcelona, així com les capitals comarcals principals i les ciutats intermèdies, mostren igualment valors inferiors o molt propers a la mitjana metropolitana. Un altre cop, tot i que en menor mesura, la massa crítica d'aquestes ciutats permet realitzar una oferta de llocs de treball suficient per retenir una part elevada de la seva població ocupada, que, per proximitat, no haurà de recórrer a mitjans mecanitzats per als seus desplaçaments laborals. Alhora, la mateixa massa crítica i la densitat urbana permeten dotar-se de serveis de transport col-lectiu, amb la qual cosa s'absorbeix una bona part dels desplaçaments en vehicle privat.

A l'altre extrem, hi trobem aquells municipis on el consum de carburant supera els 0,4 i fins i tot els 0,5 kep per ocupat (i que en casos com ara Pontons

Mapa 1. Consum de carburants per ocupat en els desplaçaments per mobilitat laboral dels municipis metropolitans (any 2015)

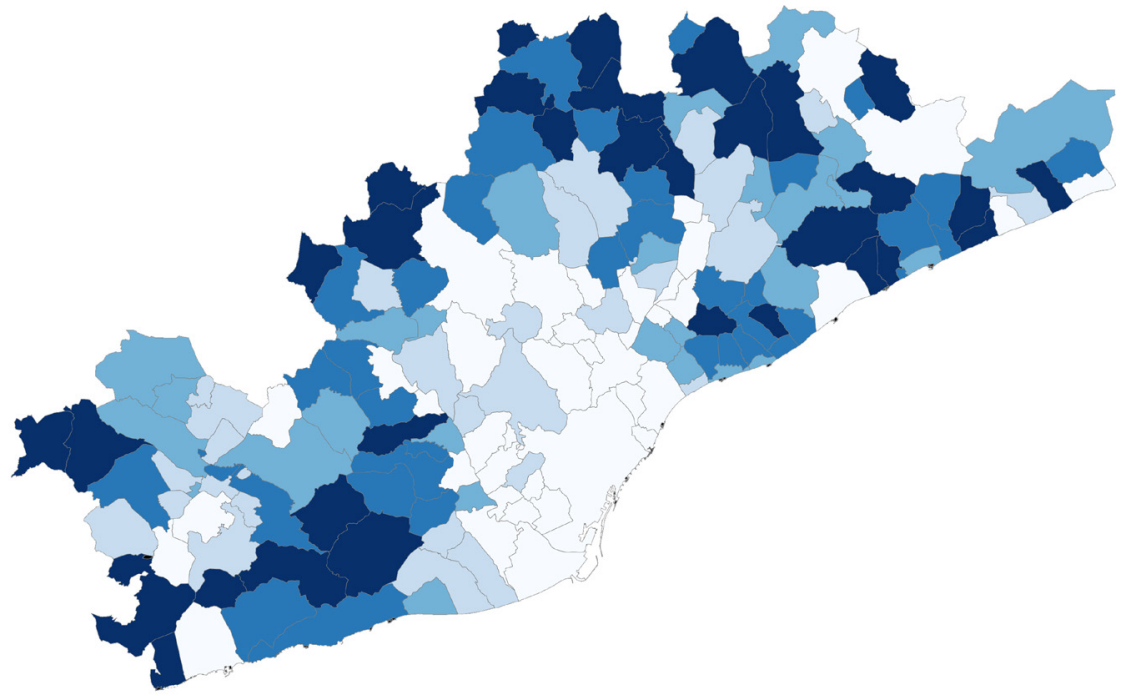

Font: elaboració pròpia. 


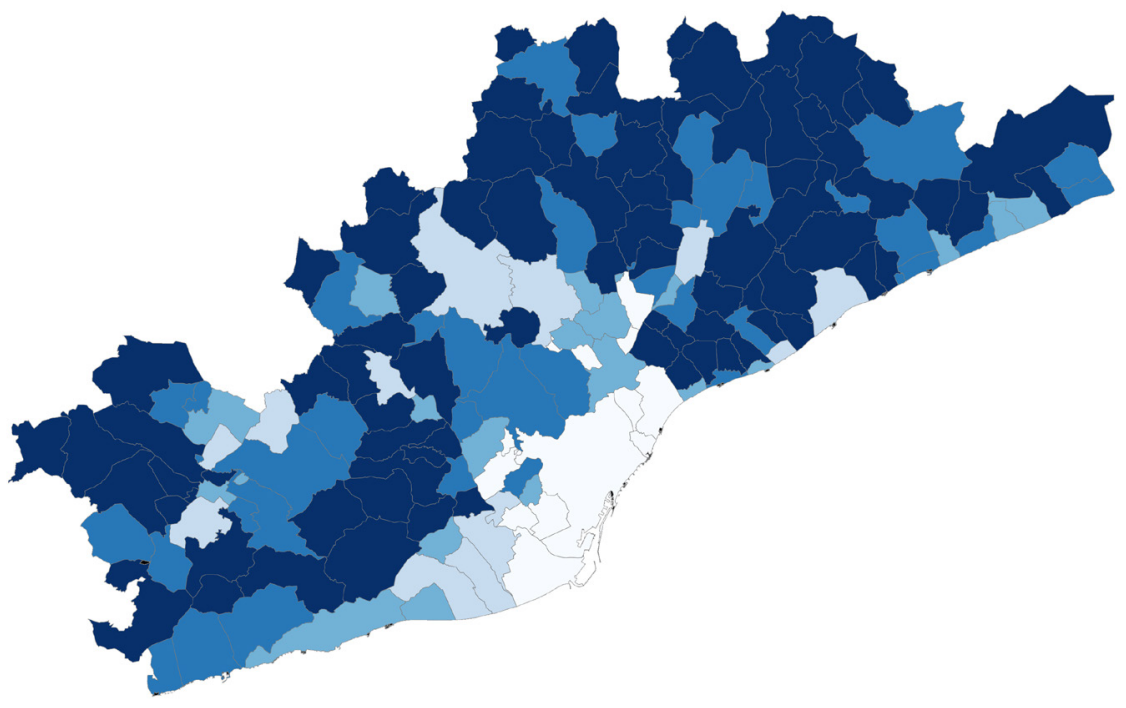

Font: elaboració pròpia.

o Sant Vicenç de Montalt arriba gairebé al 0,7). Moltes vegades, es tracta de municipis poc poblats, com ara Granera, Gallifa, Tagamanent, Montseny o Santa Fe del Penedès, que no arriben als 200 ocupats. D'altres, en canvi, són municipis grans o mitjans, si bé amb una marcada especialització residencial.

Aquestes diferències en el consum de carburants dels municipis metropolitans esdevenen encara més interessants quan es comparen amb la proporció de sòl dispers i de baixa densitat sobre el conjunt de sòl residencial. Tal com es pot comprovar en el mapa 2, gairebé dues terceres parts $(64,35 \%)$ del sòl residencial de la regió metropolitana de Barcelona correspon a aquestes categories característiques de la dispersió i la baixa densitat. Altre cop, els municipis de Barcelona i del seu entorn més proper tenen característiques clarament diferenciades i mostren proporcions de sòl de baixa densitat molt per sota de la mitjana: la Llagosta, Cornellà de Llobregat, Ripollet i Barcelona presenten valors inferiors al 10\%; l'Hospitalet de Llobregat, inferiors al 3\%, i Badia del Vallès no arriba a l'1\%. De manera similar, les capitals comarcals principals presenten valors sensiblement més baixos que els dels municipis del seu voltant. Per contra, a municipis com ara Vacarisses, Bigues i Riells, Dosrius, Lliçà d'Amunt, Matadepera o l'Ametlla del Vallès, el sòl residencial dispers i de baixa densitat representa més del 98\% del total; a Sant Pere de Vilamajor, Canyelles, Olivella i Tiana, més del 99\%, i a les Cabanyes i Tagamanent és el 100\%. 
Mapa 3. Relació entre consum de carburants per ocupat i sòl residencial dispers i de baixa densitat als municipis metropolitans (any 2015)

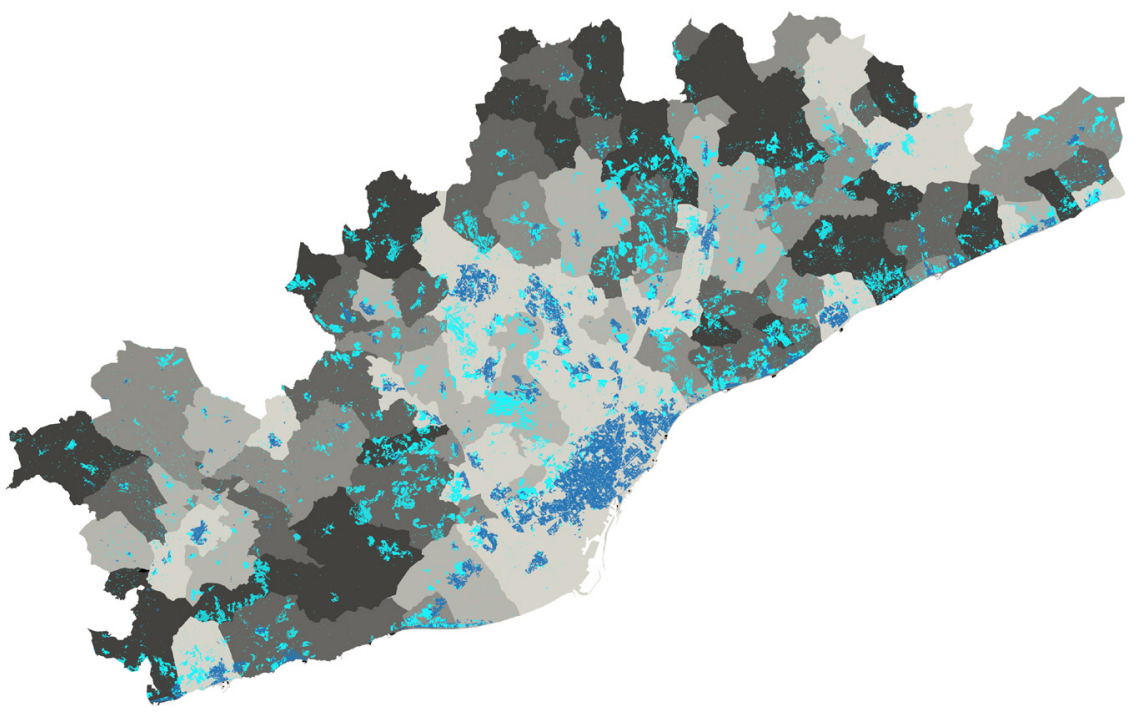

Font: elaboració pròpia.

La identificació del consum de carburant per ocupat i de la proporció de sòl residencial dispers i de baixa densitat de cada municipi permet conèixer el nivell de relació entre totes dues variables. Aquesta relació pot observar-se al mapa 3.

La quantificació d'aquesta relació es mostra al gràfic 1, on es pot observar una relació positiva entre totes dues variables, de manera que, a mesura que augmenta la proporció de sòl residencial dispers i de baixa densitat, s'incrementa el consum de carburant per ocupat.

La correlació no és, evidentment, total, la qual cosa indica que hi ha uns altres factors al costat de la forma urbana que tenen incidència en el consum de carburants, com ara la dotació de transport públic o la morfologia municipal dels llocs on van a treballar les persones que es desplacen, especialment quan es tracta d'àrees especialitzades d'activitat segregades dels continus urbans ${ }^{20}$. En tot cas, la taula permet observar clarament com si bé els municipis amb una proporció elevada de sòl residencial dispers i de baixa densitat poden tenir consums de carburants més elevats o menys elevats, cap municipi on predomina el sòl residencial dens i compacte té consums elevats.

20. A més d'aquests elements, als quals encara caldria afegir-n'hi uns altres de caire urbanístic i territorial (Papa et al., 2014), hi tenen incidència molts altres factors de tipus econòmic o social. La identificació del pes relatiu de cadascun d'aquests factors hauria requerit una anàlisi multivariable que, malgrat el seu interès, superaria l'enfocament estrictament territorial d'aquest treball. 
Gràfic 1. Relació entre consum de carburants per ocupat i sòl residencial dispers i de baixa densitat als municipis metropolitans (any 2015)

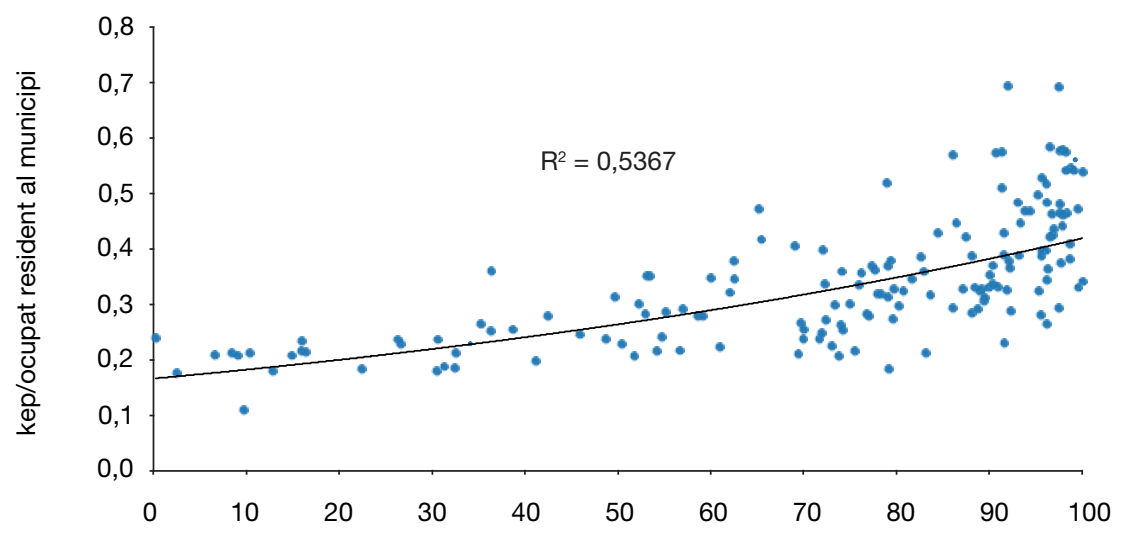

Font: elaboració pròpia.

Dit d'una altra manera, tots els consums elevats de carburants es concentren en municipis dispersos i de baixa densitat. A banda d'altres factors que hi puguin incidir, això es produeix perquè, tal com mostra la taula 1 , les pautes de mobilitat laboral d'aquestes poblacions es caracteritzen per una obertura més gran (és a dir, menys autocontenció), una distància més llarga dels desplaçaments i més tendència a utilitzar el vehicle privat que les observades en els municipis densos i compactes ${ }^{21}$.

De l'anàlisi realitzada, se'n pot concloure, doncs, que aquells municipis amb una proporció més elevada de sòl residencial dispers i de baixa densitat mostren un consum més elevat de carburants per ocupat en referència als seus desplaçaments laborals.

$\mathrm{Val}$ a dir, tanmateix, que, sobre aquests resultats, caldria aplicar segurament una correcció pel diferent repartiment modal existent en l'actualitat respecte al de l'any 2001. Així, sembla que diversos indicadors apuntin a un decrement del transport motoritzat. En primer lloc, les enquestes i les dades censals existents mostren, tenint en compte les pròpies particularitats, una pèrdua del pes relatiu del transport privat en tots els casos:

21. Cal apuntar que l'obertura relativament elevada dels municipis amb un percentatge més baix de sòl dispers i de baixa densitat és deguda, principalment, al fet que aquesta categoria aplega bona part dels municipis de l'entorn més proper a Barcelona, on l'efecte de continu urbà dilueix la importància dels límits municipals per a moltes d'aquestes poblacions que treballen a la capital catalana. De fet, la taula està elaborada a partir de la mitjana de valors municipals i no dels valors mitjans dels desplaçaments de cada grup de municipis. Si haguéssim seguit aquest segon mètode, el pes dels desplaçaments originats a Barcelona, on el percentatge d'obertura és del $22,3 \%$, hauria fet baixar substancialment el valor mitjà. 
Taula 1. Pautes de mobilitat laboral dels municipis metropolitans en funció del sòl residencial dispers i de baixa densitat (any 2015)

\begin{tabular}{ccccc}
\hline $\begin{array}{c}\text { Percentatge de } \\
\text { sòl residencial } \\
\text { dispers i de } \\
\text { baixa densitat }\end{array}$ & $\begin{array}{c}\text { \% desplaçaments } \\
\text { extra-municipals }\end{array}$ & $\begin{array}{c}\text { Distància } \\
\text { mitjana dels } \\
\text { desplaçaments }\end{array}$ & $\begin{array}{c}\% \text { de } \\
\text { desplaçaments } \\
\text { en transport } \\
\text { privat }\end{array}$ & $\begin{array}{c}\text { Consum de } \\
\text { carburant kep/ } \\
\text { ocupat }\end{array}$ \\
\hline$<20 \%$ & 65,6 & $7.679,6$ & 50,6 & 0,201 \\
$20-40 \%$ & 53,6 & $7.919,1$ & 58,9 & 0,231 \\
$40-60 \%$ & 63,0 & $9.218,5$ & 60,2 & 0,267 \\
$60-80 \%$ & 60,1 & $10.046,2$ & 64,6 & 0,312 \\
$80-100 \%$ & 67,6 & $11.859,6$ & 71,5 & 0,416 \\
\hline
\end{tabular}

Font: elaboració pròpia a partir de les dades d'Afiliacions a la Seguretat Social segons residència padronal de l'afiliat, corresponents al primer trimestre de 2015 i de la matriu de mobilitat laboral del cens de 2001 (Institut d'Estadística de Catalunya).

segons l'Enquesta de Mobilitat en Dia Feiner, aquest passaria del 55\% el 2004 al 49,1\% el 201422. L'Enquesta de Condicions de vida i hàbits de la població mostra uns resultats molt similars per al conjunt de la província de Barcelona, que passa del 54,9\% dels desplaçaments fins al treball l'any 2000 al 49,3\% el 2011. D'altra banda, les mateixes dades censals, que inclouen també els que no es desplacen i els no aplicables, atorguen al transport privat un 47,2\% dels desplaçaments laborals el $2001 \mathrm{i}$ un $44,8 \%$ el $2011^{23}$. Ara bé, l'aplicació d'un factor de correcció per tractar d'equiparar les informacions de 2001 a les actuals podria contribuir a incrementar encara més aquest marge d'error, més que no pas a reduir-lo. Així, les dades de les referències citades presenten tres limitacions fonamentals: 1) es tracta de desplaçaments per motius de treball i d'estudi conjuntament, per la qual cosa esdevé especialment complex obtenir una dada específica relativa als desplaçaments laborals; 2) malgrat que facin al-lusió a un període de temps molt proper a l'analitzat, els anys de referència no són els mateixos; 3) el desglossament modal de les dades d'aquestes enquestes tampoc és coincident amb les del cens de 2001 i, per tant, la transposició directa a la matriu mostraria igualment un biaix elevat. Per aquests motius, qualsevol intent d'actualitzar la matriu de 2001 a partir de les fonts citades hagués comportat un increment més probable del marge d'error.

En segon lloc, aquest transvasament de desplaçaments dels mitjans motoritzats individuals al transport col-lectiu o no motoritzat ha tingut un efecte real sobre el consum de carburants. Així, tal com mostra el gràfic 2 per al conjunt de la província de Barcelona, el consum de carburants per habitant l'any 2003 era molt superior a l'actual. I, malgrat que, en aquests consums,

22. Dades per l'anomenada «Mobilitat obligada» l'any $2004 \mathrm{i}$ «Mobilitat ocupacional» l'any 2014, que inclouen tant el treball com l'estudi com a motiu de desplaçament.

23. La relació d'aquests canvis en els patrons de mobilitat i la situació de crisi econòmica i social ha estat assenyalada a Nel.lo i Donat, 2014. 
Gràfic 2. Evolució de la població i el consum d'hidrocarburs a la província de Barcelona (1983-2013). Tones mètriques.

\begin{tabular}{lrrrrr}
\hline & 1983 & 1998 & 2003 & 2008 & \multicolumn{1}{c}{2013} \\
\hline Població & 4.649 .628 & 4.666 .271 & 5.052 .666 & 5.416 .447 & 5.540 .925 \\
\hline Gasolina 90 & 105.505 & & & & \\
Gasolina 96/97 & 587.300 & 532.684 & 114.933 & & \\
Gasolina 95 & & 379.118 & 655.498 & 575.071 & 469.169 \\
Gasolina 98 & 37.315 & 151.392 & 122.506 & 76.061 & 30.331 \\
Gasoil A & 412.909 & 1.239 .156 & 1.866 .027 & 2.057 .253 & 1.752 .142 \\
Biodiesel & & & & 43.535 & 3.853 \\
Total & 1.143 .029 & 2.302 .350 & 2.758 .964 & 2.751 .921 & 2.255 .495 \\
\hline Total per habitant $(\mathrm{kg})$ & 246 & 493 & 546 & 508 & 407 \\
& & & & & \\
\end{tabular}

Font: Població (1983: INE: Cifras de población: Principales series desde 1971; 1998-2013: IDESCAT: Padró municipal d'habitants). Carburants (OILGAS: Enciclopedia Nacional del Petróleo, Petrolquímica y Gas, 1984; CORES: Consumos de gasolinas, gasóleos y fuelóleos por provincias y comunidades autónomas; CNMC: Estadística de productos petroliferos).

cal comptabilitzar la totalitat de desplaçaments (tant de persones com de mercaderies) com de motivacions (per estudis, per anar a comprar, per lleure, etc.), sembla probable que la mobilitat per motiu laboral hi té igualment una incidència destacada.

En qualsevol cas, aquest ajust afectaria el consum total de carburants, de manera que, en distribuir-se equitativament entre tots els municipis, no alteraria la relació entre consum i forma urbana mostrada en el present article.

\section{Conclusions}

El treball ha mostrat la relació entre un consum més elevat de carburants per persona ocupada en els desplaçaments diaris per motiu laborals i una proporció més elevada de sòl residencial dispers i de baixa densitat de cada municipi.

L'aportació principal de l'estudi ha estat el disseny i l'aplicació d'una metodologia que permeti relacionar els consums de carburants amb uns municipis concrets i, a partir d'aquí, observar-ne les diferències eventuals en funció de la seva tipologia residencial.

La metodologia emprada permet suplir parcialment la manca de dades actuals sobre mobilitat a escala municipal i converteix les estimacions de desplaçaments resultants en consums de carburant a partir de la consideració dels mitjans de transport utilitzats i l'estimació de les distàncies recorregudes. Si bé aquesta successió d'estimacions resta precisió sobre els consums finals de 
carburant, la seva aplicació uniforme a tots els municipis metropolitans fa que la comparació sigui vàlida en termes generals.

La primera part de l'anàlisi —l'estimació de consum a partir de la matriu de mobilitat - ha permès constatar una relació fins a cert punt evident: que un consum més elevat de carburant és producte, en bona mesura, de la combinació d'un valor elevat o molt elevat en tres dels elements bàsics que caracteritzen la mobilitat, com ara l'obertura dels municipis (o inversa de l'autocontenció), les distàncies recorregudes i la proporció de desplaçaments en vehicle privat. En aquest sentit, el consum de carburant esdevé un indicador sintètic d'aquesta triple característica de la mobilitat.

La segona part de l'anàlisi — que es basa a creuar els resultats de consum amb la morfologia urbana dels municipis on s'origina la mobilitat- ha mostrat també l'existència d'una relació entre totes dues variables, de manera que, als municipis on predominen els teixits residencials dispersos i de baixa densitat, el consum de carburant per ocupat resident és molt superior que el de la resta. La consideració únicament de la morfologia de les poblacions estudiades en l'anàlisi no permet valorar el pes d'aquesta variable respecte a d'altres que hi poden incidir, però la relació entre consum de carburant i forma urbana esdevé, en qualsevol cas, evident.

Aquestes conclusions permeten confirmar la importància dels costos energètics i ambientals que suposa la dispersió urbana. Així mateix, indiquen la necessitat d'establir una estreta interrelació entre les polítiques de transport, de dotació d'infraestructures i de planejament dels usos del sòl.

\section{Referències bibliogràfiques}

AADD (1998). Cohesió, centralitat i cohesió iterativa: Àrees funcionals a Catalunya, 1981-1986-1991 i avanç 1996. Barcelona: Direcció General d'Ordenació del Territori i Urbanisme.

Autoritat del Transport Metropolità (2014). EMEF 2014. La mobilitat a l'àmbit del sistema tarifari integrat de l'àrea de Barcelona: Enquesta de mobilitat en dia feiner. Barcelona.

- (2015). Pla director de Mobilitat de la Regió Metropolitana de Barcelona 2013-2018. Barcelona.

Banister, David (2012). «Assessing the reality: Transport and land use planning to achieve sustainability». The Journal of Transport and Land Use, 5 (3), 1-14.

Carrera, Josep Maria (dir.) (2012). «Informe de diagnosi i recomanacions dels elements territorials de la regió metropolitana de Barcelona i la seva relació amb la mobilitat». Estudi instrumental per al Pla Director de Mobilitat de la Regió Metropolitana de Barcelona 2013-2018. Barcelona: Autoritat del Transport Metropolità.

Carrera, Josep Maria i López, Joan (2006). «Territori, població i localització d'activitats». Estudi instrumental per al Pla Director de Mobilitat de la Regió Metropolitana de Barcelona 2008-2012. Barcelona: Autoritat del Transport Metropolità.

CASTAÑER, Margarida (1994a). «Una nova dimensió de la xarxa de ciutats a Catalunya: Les àrees de cohesió». Documents d'Anàlisi Geogràfica, 25, 63-67. 
- (1994b). «La ciudad real en Catalunya: Las áreas de cohesión». Ciudad y Territorio, II (99), tercera època, 101-114.

Cervero, Robert i Duncan, Michael (2006). «Which Reduces Vehicle Travel More: Jobs-Housing Balance or Retail-Housing Mixing?». Journal of the American Planning Association [en línia] 72 (4), 475-490. <http://dx.doi.org/10.1080/01944360608976767>

Clusa, Joaquim (1995). "La mobilitat obligada i els àmbits funcionals a la Regió Metropolitana de Barcelona». Papers: Regió Metropolitana de Barcelona, 24, 51-68. Barcelona. Institut d'Estudis Metropolitans de Barcelona.

Direcció de Serveis Ambientals de l’AMB. Barcelona Regional (2014). Balanços energètics dels municipis metropolitans. Barcelona: AMB.

Dirección General de Tráfico (2014). Parque de vehículos: Anuario 2014 [en línia]. $<$ www.dgt.es/es/seguridad-vial/estadisticas-e-indicadores/parque-vehiculos/tablasestadisticas/2014/>.

Entitat Metropolitana del Transport (1996). Encuesta de movilidad en el área de Barcelona - EMAB '94 (Ámbito Territorial de la EMT). Barcelona: EMTTMB.

Esteban, Manuel (1989). Distribució de la mobilitat per treball a la regió metropolitana de Barcelona. Barcelona: Mancomunitat de Municipis de l'Àrea Metropolitana de Barcelona.

Fuente, Samuel de la (2007). «La influencia de la forma urbana en la movilidad: Un estudio para el caso de Cataluña». Documents de Recerca del Programa de Doctorado en Economía Aplicada. Bellaterra: Universitat Autònoma de Barcelona.

- (2012). «La influencia de la forma urbana en la movilidad: Un análisis empírico para las áreas urbanas de Madrid y Barcelona». Tesi doctoral. Bellaterra: Departament d'Economia Aplicada. Universitat Autònoma de Barcelona.

Generalitat de Catalunya. Departament de Política Territorial i Obres Públiques (1995). Pla territorial general de Catalunya. Barcelona.

- (2008). Pla director de mobilitat de la regió metropolitana de Barcelona. Barcelona.

- (2010). Pla territorial metropolità de Barcelona. Barcelona.

Gobierno de España (2002). «Real Decreto 837/2002, de 2 de agosto, por el que se regula la información relativa al consumo de combustible y a las emisiones de $\mathrm{CO}_{2}$ de los turismos nuevos que se pongan a la venta o se ofrezcan en arrendamiento financiero en territorio español». BOE, 185 (3 d'agost), 28851 a 28856.

- (2012). «Resolución de 24 de septiembre de 2012, de la Secretaría General de Industria y de la Pequeña y Mediana Empresa, por la que se actualiza el anexo I. 2 del Real Decreto 837/2002, de 2 de agosto, en lo relativo a los parámetros que determinan la media del consumo de los vehículos de turismos nuevos que se pongan a la venta o se ofrezcan en arrendamiento financiero en territorio español», BOE, 233 (27 de setembre), 68723 i 68724.

Grup d’Anàlisi i Planificació Territorial i Ambiental (2005). Mobilitat laboral $i$ àrees de cohesió a Catalunya. 2001 [CD-ROM].

Hickman, Robin i Banister, David (2007). "Transport and reduced energy consumption: What role can urban planning play?». Working paper, 1026. Oxford: Transport Studies Unit. Oxford University Centre for the Environment.

Indovina, Francesco (coord.) (2007). La ciudad de baja densidad: Lógicas, gestión y contención. Barcelona: Diputació de Barcelona.

Institut Cerdà (2012). «Emissions de gasos efecte hivernacle i la qualitat de l'aire de la mobilitat de la Regió Metropolitana de Barcelona: Seguiment de l'evolució 
de les emissions 2006-2010». Estudi instrumental per al Pla Director de Mobilitat. Barcelona: Autoritat Metropolitana de Transport.

Institut d'Estudis Regionals i Metropolitans de Barcelona (2002). Enquesta de la regió de Barcelona, 2000: Dades estadístiques bàsiques 2000, 1. Barcelona.

- (2004). Enquesta de mobilitat en dia feiner (EMEF'04). Barcelona.

Karathodorou, Niovi; Graham, Daniel J. i Noland, Robert B. (2010). «Estimating the effect of urban density on fuel demand». Energy Economics [en línia], 32, 86-92. <http://dx.doi.org/10.1016/j.eneco.2009.05.005>

LluCh, Enric et al. (1968). «L'evolució de les àrees de trànsit dels autobusos de línia a Catalunya. 1934-1962». Banca Catalana: Publicación de Información Económica, 8, 16-28.

López, Joan (1998). «La mobilitat per motiu d'estudi als municipis de la província de Barcelona». A: RocA, Joan (coord.). La formació del cinturó industrial de Barcelona. Barcelona: Institut Municipal d'Història-Proa, 461-480.

- (2003). «La mobilitat de persones a la regió metropolitana de Barcelona». Papers: Regió Metropolitana de Barcelona, 38. Institut d'Estudis Regionals i Metropolitans de Barcelona. Barcelona.

Marmolejo, Carlos i Tornés, Moira (2015). «¿Reduce el policentrismo la movilidad laboral?: Un análisis para las siete grandes áreas metropolitanas en España». Scripta Nova, XVIII (500). Barcelona: Universitat de Barcelona.

Ministerio de Medio Ambiente y Medio Rural y Marino. Ministerio de Fomento (2011). Estrategia española de sostenibildad urbana y local.

Miralles, Carme (1997). Transport i ciutat: Reflexió sobre la Barcelona contemporània. Bellaterra: Universitat Autònoma de Barcelona. Versió castellana: Ciudad y transporte: El binomio imperfecto. Barcelona: Ariel, 2002.

MuÑIz, Ivan i Galindo Anna (2005). "Urban form and the ecological footpint of commuting: The case of Barcelona». Ecological Economics, 55, 499-514.

Muñoz, Francesc (ed.) (2011). Estrategias para la ciudad de baja densidad: De la contención a la gestión. Barcelona: Diputació de Barcelona.

NeL.LO, Oriol (1995). «Dinàmiques territorials i mobilitat urbana a la regió metropolitana de Barcelona». Papers: Regió Metropolitana de Barcelona, 24 (abril), 9-37. Barcelona. Institut d'Estudis Metropolitans de Barcelona.

- (dir.) (1999). Anàlisi de la mobilitat obligada dels municipis de la província de Barcelona 1986-1996. Servei de Cooperació Local de la Diputació de Barcelona.

- (2011a). «Estrategias para la contención y gestión de las urbanizaciones de baja densidad en Cataluña». Ciudad y Territorio: Estudios Territoriales, XLIII (167).

- (2011b). «Les urbanitzacions amb dèficits urbanístics: De la utopia a la gestió». A: MuÑoz, Francesc (ed.). Estrategias para la ciudad de baja densidad: De la contención a la gestión. Barcelona: Diputació de Barcelona.

NeL.LO, Oriol i Donat, Carles (2014). «Los efectos territoriales de la crisis en la región metropolitana de Barcelona». A: Albertos, Juan M. i Sánchez, José L. (ed.). Geografía de la crisis econòmica en España [en línia]. València: Universitat de València, 565-608.

<http://dx.doi.org/10.1111/ecge.12090>

NeL·Lo, Oriol; López, Joan i Piqué, Joan Miquel (2002). «Las redes emergentes de articulación del territorio en la región de Barcelona: Un análisis de la movilidad obligada, 1986-1996». A: Subirats, Joan (coord.). Redes, territorios y gobierno. Barcelona: Diputació de Barcelona.

Observatori de Costos del Transport Discrecional de Viatgers a Catalunya (2015). Butlleti de Transports, 72 (abril). 
Observatori del Transport Regular de Viatgers per Carretera a Catalunya (2003). Butlleti de Transports, 26 (desembre).

OILGAS (1984). Enciclopedia Nacional del Petróleo, Petroquímica y Gas. Madrid: Sede Técnica.

Palacio, Gabriel (coord.) (1995). Els mercats de treball de Catalunya, 1981-19861991. Barcelona: Generalitat de Catalunya. Direcció General de Planificació i Acció Territorial.

Papa, Rocco; Gargiulo, Carmela i Angiello, Gennaro (2014). «The factors influencing transport energy consumption in urban areas: A review». Journal of Land Use, Mobility and the Environment, número especial. Nàpols. University of Naples Federico II.

Riera, Pilar (1991). "Les ciutats i el territori: Balanç dels estudis sobre el sistema urbà de Catalunya 1931-1991». Actes del Primer Congrés Català de Geografia. Vol. II. Ponències. Barcelona: Societat Catalana de Geografia.

Roca Cladera, Josep (dir.) (1997). La delimitació de l'àrea metropolitana de Barcelona. Barcelona: Centre de Política del Sòl i Valoracions.

- (dir.) (1998a). Mobilitat a Catalunya 1991-1996: Cap a un model de mobilitat insostenible? Barcelona: Centre de Política del Sòl i Valoracions.

- (1998b). Evolució de l'estructura urbana a Catalunya 1991-1996: Impacte dels canvis experimentats en la distribució espacial de la població i la mobilitat per treball en el sistema català de ciutats. Barcelona: Centre de Política del Sòl i Valoracions.

Rueda, Salvador (2002). «Els costos ambientals dels models urbans dispersos». Papers: Regió Metropolitana de Barcelona, 36. Barcelona: Institut d'Estudis Regionals i Metropolitans de Barcelona (maig).

SENER (2012). «Costos socials i ambientals de la mobilitat a la RMB per a l'any 2010». Estudi instrumental per al Pla Director de Mobilitat. Barcelona: Autoritat Metropolitana de Transport.

Shim, Gyo-Eon; Rhee, Sung-Mo; Ahn, Kun-Hyuck i Chung, Sung-Bong (2006). "The relationship between the characteristics of transportation energy consumption and urban form». The Annals of Regional Science, 40 (2), 351-367.

Trullén, Joan (dir.) (2015). Creixement inclusiu: El gran repte estratègic metropolità. Anuari Metropolità de Barcelona 2014. Bellaterra: Institut d'Estudis Regionals i Metropolitans de Barcelona.

Van de Covering, Paul i Schwanen, Tim (2006). «Re-evalutaing the impact of urban form on travel patterns in Europe and North-America». Transport Policy [en línia], 13, 229-239. <http://dx.doi.org/10.1016/j.tranpol.2005.10.001>

Villalante, Manel; Pérez, Maite i Jiménez, Cristina (2014). «Patrons, tendències i estratègies de la mobilitat metropolitana». Quaderns del PDU Metropolità, 8. Barcelona: Àrea Metropolitana de Barcelona.

\section{Portals web utilitzats per obtenir-ne dades i paràmetres de referència}

Centre de Recerca Ecològica i Aplicacions Forestals (CREAF): <www.creaf.uab.es/ mcsc/descriptiu.htm>

Comisión Nacional de los Mercados y la Competencia (CNMC): <https:/www.cnmc.es/>

Corporación de Reservas Estratégicas de Productos Petrolíferos (CORES): <www. cores.es/es/estadisticas> 
Institut d'Estadística de Catalunya (IDESCAT): <www.idescat.cat>

Institut Cartogràfic i Geològic de Catalunya (ICGC): <www.icc.cat>

Instituto Nacional de Estadística (INE): <www.ine.es>

Instituto para la Diversificación y Ahorro de la Energía (IDAE): <www.idae.es>

Masmoto: <www.masmoto.net>

Universitat Autònoma de Barcelona: <www.uab.cat/web/la-mobilitat-a-la-uab/enquesta-de-mobilitat-1255501888126.html> 


\section{Annex. Exemple d'estimació del consum de carburant per a un flux de mobilitat laboral (de Sabadell a Cerdanyola del Vallès)}

\begin{tabular}{|c|c|c|c|c|c|c|c|c|}
\hline \multirow[b]{3}{*}{ Mitjà de transport } & \multicolumn{2}{|c|}{ Actualització del flux } & \multirow{2}{*}{$\begin{array}{c}\text { Km recorreguts } \\
\text { Distància km } \\
6,70630\end{array}$} & \multicolumn{5}{|c|}{ Repartiment de modes per carburant } \\
\hline & \multicolumn{2}{|c|}{$\begin{array}{l}\text { Total POR Sabadell } 2001 \\
\text { Total afiliats Sabadell } 2015 \\
\text { Coeficient 2015/2001 }\end{array}$} & & \multicolumn{2}{|c|}{$\begin{array}{l}\text { \% Cotxes Gasolina } \\
\% \text { Cotxes Gasoil } \\
\% \text { Motos Gasolina } \\
\% \text { Autobusos Gasoil }\end{array}$} & \multicolumn{3}{|r|}{$\begin{array}{r}49,7680 \\
50,2320 \\
100 \\
100\end{array}$} \\
\hline & $\begin{array}{c}\text { Flux } 2001 \\
\text { (segons } \\
\text { matriu EM0) }\end{array}$ & $\begin{array}{c}\text { Flux 2015 } \\
\text { (Flux 2001 * } \\
\text { Coeficient 2015/2001) }\end{array}$ & $\begin{array}{l}\text { km totals } \\
\text { (Flux 2015 * } \\
\text { Distància) }\end{array}$ & $\begin{array}{r}\text { Cotxes } \\
\text { Gasolina }\end{array}$ & $\begin{array}{l}\text { Cotxes } \\
\text { Gasoil }\end{array}$ & $\begin{array}{l}\text { Motos } \\
\text { Gasolina }\end{array}$ & $\begin{array}{l}\text { Busos } \\
\text { Gasoil }\end{array}$ & Total \\
\hline Cotxe com a conductor & 843 & 824,7 & $5.530,9$ & 0,4977 & 0,5023 & & & 1,00 \\
\hline Cotxe com a conductor + Cotxe com a passatger & 7 & 6,8 & 45,9 & 0,2488 & 0,2512 & & & 0,50 \\
\hline Cotxe com a conductor + Autobús & 7 & 6,8 & 45,9 & 0,2488 & 0,2512 & & 0,5000 & 1,00 \\
\hline Cotxe com a conductor + Metro & 0 & 0,0 & 0,0 & 0,2488 & 0,2512 & & & 0,50 \\
\hline Cotxe com a conductor + Moto & 2 & 2,0 & 13,1 & 0,2488 & 0,2512 & 0,5000 & & 1,00 \\
\hline Cotxe com a conductor + RENFE & 12 & 11,7 & 78,7 & 0,2488 & 0,2512 & & & 0,50 \\
\hline Cotxe com a conductor + Altres trens & 21 & 20,5 & 137,8 & 0,2488 & 0,2512 & & & 0,50 \\
\hline Cotxe com a conductor + Bicicleta & 3 & 2,9 & 19,7 & 0,2488 & 0,2512 & & & 0,50 \\
\hline Cotxe com a conductor + Altres mitjans & 0 & 0,0 & 0,0 & 0,2488 & 0,2512 & & & 0,50 \\
\hline Cotxe com a passatger + Moto & 0 & 0,0 & 0,0 & & & 0,5000 & & 0,50 \\
\hline Cotxe com a passatger + Autobús & 8 & 7,8 & 52,5 & & & & 0,5000 & 0,50 \\
\hline Moto & 23 & 22,5 & 150,9 & & & 1,0000 & & 1,00 \\
\hline Moto + RENFE & 0 & 0,0 & 0,0 & & & 0,5000 & & 0,50 \\
\hline Moto + Altres trens & 0 & 0,0 & 0,0 & & & 0,5000 & & 0,50 \\
\hline Moto + Bicicleta & 0 & 0,0 & 0,0 & & & 0,5000 & & 0,50 \\
\hline Moto + Altres mitjans & 2 & 2,0 & 13,1 & & & 0,5000 & & 0,50 \\
\hline Metro + Moto & 0 & 0,0 & 0,0 & & & 0,5000 & & 0,50 \\
\hline Autobús & 57 & 55,8 & 374,0 & & & & 1,0000 & 1,00 \\
\hline Autobús + Metro & 0 & 0,0 & 0,0 & & & & 0,5000 & 0,50 \\
\hline Autobús + Moto & 0 & 0,0 & 0,0 & & & 0,5000 & 0,5000 & 1,00 \\
\hline Autobús + RENFE & 16 & 15,7 & 105,0 & & & & 0,5000 & 0,50 \\
\hline Autobús + Altres trens & 24 & 23,5 & 157,5 & & & & 0,5000 & 0,50 \\
\hline Autobús + Bicicleta & 0 & 0,0 & 0,0 & & & & 0,5000 & 0,50 \\
\hline Autobús + Altres mitjans & 0 & 0,0 & 0,0 & & & & 0,5000 & 0,50 \\
\hline Cotxe com a passatger & 62 & 60,7 & 406,8 & & & & & 0,00 \\
\hline Cotxe com a passatger + Metro & 0 & 0,0 & 0,0 & & & & & 0,00 \\
\hline Cotxe com a passatger + RENFE & 8 & 7,8 & 52,5 & & & & & 0,00 \\
\hline Cotxe com a passatger + Altres trens & 3 & 2,9 & 19,7 & & & & & 0,00 \\
\hline Cotxe com a passatger + Bicicleta & 0 & 0,0 & 0,0 & & & & & 0,00 \\
\hline Cotxe com a passatger + Altres mitjans & 0 & 0,0 & 0,0 & & & & & 0,00 \\
\hline Metro & 0 & 0,0 & 0,0 & & & & & 0,00 \\
\hline Metro + Caminant & 0 & 0,0 & 0,0 & & & & & 0,00 \\
\hline Metro + RENFE & 0 & 0,0 & 0,0 & & & & & 0,00 \\
\hline Metro + Altres trens & 0 & 0,0 & 0,0 & & & & & 0,00 \\
\hline Metro + Bicicleta & 0 & 0,0 & 0,0 & & & & & 0,00 \\
\hline Metro + Altres mitjans & 0 & 0,0 & 0,0 & & & & & 0,00 \\
\hline Caminant & 1 & 1,0 & 6,6 & & & & & 0,00 \\
\hline RENFE & 58 & 56,7 & 380,5 & & & & & 0,00 \\
\hline RENFE + Altres trens & 0 & 0,0 & 0,0 & & & & & 0,00 \\
\hline RENFE + Bicicleta & 0 & 0,0 & 0,0 & & & & & 0,00 \\
\hline RENFE + Altres mitjans & 0 & 0,0 & 0,0 & & & & & 0,00 \\
\hline Altres trens & 112 & 109,6 & 734,8 & & & & & 0,00 \\
\hline Altres trens + Bicicleta & 3 & 2,9 & 19,7 & & & & & 0,00 \\
\hline Altres trens + Altres mitjans & 0 & 0,0 & 0,0 & & & & & 0,00 \\
\hline Bicicleta & 0 & 0,0 & 0,0 & & & & & 0,00 \\
\hline Bicicleta + Altres mitjans & 0 & 0,0 & 0,0 & & & & & 0,00 \\
\hline \multirow[t]{2}{*}{ Altres mitjans } & 3 & 2,9 & 19,7 & & & & & 0,00 \\
\hline & & & & & & & & 0,0 \\
\hline No aplicable & 5 & 4,9 & 32,8 & & & & & \\
\hline Total & 1.280 & $1.252,3$ & $8.398,1$ & & & & & \\
\hline
\end{tabular}




\begin{tabular}{|c|c|c|c|c|c|c|c|c|c|c|c|c|c|c|c|}
\hline \multicolumn{5}{|c|}{ Repartiment de modes per carburant } & \multicolumn{4}{|c|}{ Consum } & \multicolumn{6}{|c|}{ Consum per plaça } & \multirow{2}{*}{$\begin{array}{l}\text { Consum total d'energia } \\
\begin{array}{ll}\text { kep/l gasolina } & 0,7752 \\
\text { kep/l gasoil } & 0,8467\end{array}\end{array}$} \\
\hline & & & & & \multicolumn{3}{|c|}{$\begin{array}{l}\text { litres/100 km cotxes Gasolina } \\
\text { litres/100 km cotxes Gasoil } \\
\text { litres/100 km Motos Gasolina } \\
\text { litres/100 km Autobus Gasoil }\end{array}$} & $\begin{array}{r}7,975 \\
5,784 \\
3 \\
32,71\end{array}$ & & & & & & & \\
\hline \multicolumn{5}{|c|}{$\mathrm{km}$ per carburant } & \multicolumn{4}{|c|}{ litres de combustible consumits } & \multicolumn{4}{|c|}{ places/ vehicle } & \multicolumn{2}{|c|}{ litres/plaça } & \multirow[b]{2}{*}{$\begin{array}{c}\text { kilos equivalents } \\
\text { de petroli }\end{array}$} \\
\hline $\begin{array}{c}\text { Cotxes } \\
\text { Gasolina }\end{array}$ & $\begin{array}{l}\text { Cotxes } \\
\text { Gasoil }\end{array}$ & $\begin{array}{c}\text { Motos } \\
\text { Gasolina }\end{array}$ & $\begin{array}{l}\text { Busos } \\
\text { Gasoil }\end{array}$ & Total & $\begin{array}{c}\text { Cotxes } \\
\text { Gasolina }\end{array}$ & $\begin{array}{l}\text { Cotxes } \\
\text { Gasoil }\end{array}$ & $\begin{array}{c}\text { Motos } \\
\text { Gasolina }\end{array}$ & $\begin{array}{l}\text { Busos } \\
\text { Gasoil }\end{array}$ & $\begin{array}{c}\text { Cotxes } \\
\text { Gasolina }\end{array}$ & $\begin{array}{l}\text { Cotxes } \\
\text { Gasoil }\end{array}$ & $\begin{array}{c}\text { Motos } \\
\text { Gasolina }\end{array}$ & $\begin{array}{l}\text { Busos } \\
\text { Gasoil }\end{array}$ & Gasolina & Gasoil & \\
\hline $2.752,6$ & $2.778,3$ & 0,0 & 0,0 & $5.530,9$ & 219,533 & 160,700 & 0,000 & 0,000 & 1 & 1 & & & 219,533 & 160,700 & 306,252 \\
\hline 11,4 & 11,5 & 0,0 & 0,0 & 23,0 & 0,911 & 0,667 & 0,000 & 0,000 & 1 & 1 & & & 0,911 & 0,667 & 1,272 \\
\hline 11,4 & 11,5 & 0,0 & 23,0 & 45,9 & 0,911 & 0,667 & 0,000 & 7,511 & 1 & 1 & & 0,055 & 0,911 & 1,078 & 1,619 \\
\hline 0,0 & 0,0 & 0,0 & 0,0 & 0,0 & 0,000 & 0,000 & 0,000 & 0,000 & 1 & 1 & & & 0,000 & 0,000 & 0,000 \\
\hline 3,3 & 3,3 & 6,6 & 0,0 & 13,1 & 0,260 & 0,191 & 0,197 & 0,000 & 1 & 1 & 1 & & 0,457 & 0,191 & 0,516 \\
\hline 19,6 & 19,8 & 0,0 & 0,0 & 39,4 & 1,563 & 1,144 & 0,000 & 0,000 & 1 & 1 & & & 1,563 & 1,144 & 2,180 \\
\hline 34,3 & 34,6 & 0,0 & 0,0 & 68,9 & 2,734 & 2,002 & 0,000 & 0,000 & 1 & 1 & & & 2,734 & 2,002 & 3,815 \\
\hline 4,9 & 4,9 & 0,0 & 0,0 & 9,8 & 0,391 & 0,286 & 0,000 & 0,000 & 1 & 1 & & & 0,391 & 0,286 & 0,545 \\
\hline 0,0 & 0,0 & 0,0 & 0,0 & 0,0 & 0,000 & 0,000 & 0,000 & 0,000 & 1 & 1 & & & 0,000 & 0,000 & 0,000 \\
\hline 0,0 & 0,0 & 0,0 & 0,0 & 0,0 & 0,000 & 0,000 & 0,000 & 0,000 & & & 1 & & 0,000 & 0,000 & 0,000 \\
\hline 0,0 & 0,0 & 0,0 & 26,2 & 26,2 & 0,000 & 0,000 & 0,000 & 8,584 & & & & 0,055 & 0,000 & 0,469 & 0,397 \\
\hline 0,0 & 0,0 & 150,9 & 0,0 & 150,9 & 0,000 & 0,000 & 4,527 & 0,000 & & & 1 & & 4,527 & 0,000 & 3,509 \\
\hline 0,0 & 0,0 & 0,0 & 0,0 & 0,0 & 0,000 & 0,000 & 0,000 & 0,000 & & & 1 & & 0,000 & 0,000 & 0,000 \\
\hline 0,0 & 0,0 & 0,0 & 0,0 & 0,0 & 0,000 & 0,000 & 0,000 & 0,000 & & & 1 & & 0,000 & 0,000 & 0,000 \\
\hline 0,0 & 0,0 & 0,0 & 0,0 & 0,0 & 0,000 & 0,000 & 0,000 & 0,000 & & & 1 & & 0,000 & 0,000 & 0,000 \\
\hline 0,0 & 0,0 & 6,6 & 0,0 & 6,6 & 0,000 & 0,000 & 0,197 & 0,000 & & & 1 & & 0,197 & 0,000 & 0,153 \\
\hline 0,0 & 0,0 & 0,0 & 0,0 & 0,0 & 0,000 & 0,000 & 0,000 & 0,000 & & & 1 & & 0,000 & 0,000 & 0,000 \\
\hline 0,0 & 0,0 & 0,0 & 374,0 & 374,0 & 0,000 & 0,000 & 0,000 & 122,328 & & & & 0,055 & 0,000 & 6,688 & 5,663 \\
\hline 0,0 & 0,0 & 0,0 & 0,0 & 0,0 & 0,000 & 0,000 & 0,000 & 0,000 & & & & 0,055 & 0,000 & 0,000 & 0,000 \\
\hline 0,0 & 0,0 & 0,0 & 0,0 & 0,0 & 0,000 & 0,000 & 0,000 & 0,000 & & & 1 & 0,055 & 0,000 & 0,000 & 0,000 \\
\hline 0,0 & 0,0 & 0,0 & 52,5 & 52,5 & 0,000 & 0,000 & 0,000 & 17,169 & & & & 0,055 & 0,000 & 0,939 & 0,795 \\
\hline 0,0 & 0,0 & 0,0 & 78,7 & 78,7 & 0,000 & 0,000 & 0,000 & 25,753 & & & & 0,055 & 0,000 & 1,408 & 1,192 \\
\hline 0,0 & 0,0 & 0,0 & 0,0 & 0,0 & 0,000 & 0,000 & 0,000 & 0,000 & & & & 0,055 & 0,000 & 0,000 & 0,000 \\
\hline 0,0 & 0,0 & 0,0 & 0,0 & 0,0 & 0,000 & 0,000 & 0,000 & 0,000 & & & & 0,055 & 0,000 & 0,000 & 0,000 \\
\hline 0,0 & 0,0 & 0,0 & 0,0 & 0,0 & 0,000 & 0,000 & 0,000 & 0,000 & & & & & 0,000 & 0,000 & 0,000 \\
\hline 0,0 & 0,0 & 0,0 & 0,0 & 0,0 & 0,000 & 0,000 & 0,000 & 0,000 & & & & & 0,000 & 0,000 & 0,000 \\
\hline 0,0 & 0,0 & 0,0 & 0,0 & 0,0 & 0,000 & 0,000 & 0,000 & 0,000 & & & & & 0,000 & 0,000 & 0,000 \\
\hline 0,0 & 0,0 & 0,0 & 0,0 & 0,0 & 0,000 & 0,000 & 0,000 & 0,000 & & & & & 0,000 & 0,000 & 0,000 \\
\hline 0,0 & 0,0 & 0,0 & 0,0 & 0,0 & 0,000 & 0,000 & 0,000 & 0,000 & & & & & 0,000 & 0,000 & 0,000 \\
\hline 0,0 & 0,0 & 0,0 & 0,0 & 0,0 & 0,000 & 0,000 & 0,000 & 0,000 & & & & & 0,000 & 0,000 & 0,000 \\
\hline 0,0 & 0,0 & 0,0 & 0,0 & 0,0 & 0,000 & 0,000 & 0,000 & 0,000 & & & & & 0,000 & 0,000 & 0,000 \\
\hline 0,0 & 0,0 & 0,0 & 0,0 & 0,0 & 0,000 & 0,000 & 0,000 & 0,000 & & & & & 0,000 & 0,000 & 0,000 \\
\hline 0,0 & 0,0 & 0,0 & 0,0 & 0,0 & 0,000 & 0,000 & 0,000 & 0,000 & & & & & 0,000 & 0,000 & 0,000 \\
\hline 0,0 & 0,0 & 0,0 & 0,0 & 0,0 & 0,000 & 0,000 & 0,000 & 0,000 & & & & & 0,000 & 0,000 & 0,000 \\
\hline 0,0 & 0,0 & 0,0 & 0,0 & 0,0 & 0,000 & 0,000 & 0,000 & 0,000 & & & & & 0,000 & 0,000 & 0,000 \\
\hline 0,0 & 0,0 & 0,0 & 0,0 & 0,0 & 0,000 & 0,000 & 0,000 & 0,000 & & & & & 0,000 & 0,000 & 0,000 \\
\hline 0,0 & 0,0 & 0,0 & 0,0 & 0,0 & 0,000 & 0,000 & 0,000 & 0,000 & & & & & 0,000 & 0,000 & 0,000 \\
\hline 0,0 & 0,0 & 0,0 & 0,0 & 0,0 & 0,000 & 0,000 & 0,000 & 0,000 & & & & & 0,000 & 0,000 & 0,000 \\
\hline 0,0 & 0,0 & 0,0 & 0,0 & 0,0 & 0,000 & 0,000 & 0,000 & 0,000 & & & & & 0,000 & 0,000 & 0,000 \\
\hline 0,0 & 0,0 & 0,0 & 0,0 & 0,0 & 0,000 & 0,000 & 0,000 & 0,000 & & & & & 0,000 & 0,000 & 0,000 \\
\hline 0,0 & 0,0 & 0,0 & 0,0 & 0,0 & 0,000 & 0,000 & 0,000 & 0,000 & & & & & 0,000 & 0,000 & 0,000 \\
\hline 0,0 & 0,0 & 0,0 & 0,0 & 0,0 & 0,000 & 0,000 & 0,000 & 0,000 & & & & & 0,000 & 0,000 & 0,000 \\
\hline 0,0 & 0,0 & 0,0 & 0,0 & 0,0 & 0,000 & 0,000 & 0,000 & 0,000 & & & & & 0,000 & 0,000 & 0,000 \\
\hline 0,0 & 0,0 & 0,0 & 0,0 & 0,0 & 0,000 & 0,000 & 0,000 & 0,000 & & & & & 0,000 & 0,000 & 0,000 \\
\hline 0,0 & 0,0 & 0,0 & 0,0 & 0,0 & 0,000 & 0,000 & 0,000 & 0,000 & & & & & 0,000 & 0,000 & 0,000 \\
\hline 0,0 & 0,0 & 0,0 & 0,0 & 0,0 & 0,000 & 0,000 & 0,000 & 0,000 & & & & & 0,000 & 0,000 & 0,000 \\
\hline 0,0 & 0,0 & 0,0 & 0,0 & 0,0 & 0,000 & 0,000 & 0,000 & 0,000 & & & & & 0,000 & 0,000 & 0,000 \\
\hline 0,0 & 0,0 & 0,0 & 0,0 & & 0,000 & 0,000 & 0,000 & 0,000 & & & & & 0,000 & 0,000 & 0,000 \\
\hline $2.837,5$ & $2.864,0$ & 164,0 & 554,4 & $6.420,0$ & 226,3 & 165,7 & 4,9 & 181,3 & & & & & & & 327,907 \\
\hline
\end{tabular}

